\title{
Transformations in understanding the health impacts of air pollutants in the $20^{\text {th }}$ century
}

\author{
P. Brimblecombe \\ School of Environmental Sciences, University of East Anglia, Norwich NR4 7TJ, UK
}

\begin{abstract}
The transformations of air pollution in the $20^{\text {th }}$ century are well known. The century opened with urban atmospheres polluted by the combustion products of burning coal: smoke and sulfur dioxide. At the millennium these pollutants had almost vanished, replaced by the pollutants, both primary and secondary, a function of fossil-fuelled vehicles. However transitions in terms of health outcomes have been equally dramatic. Fine particulate matter causes notable cardiovascular problems such as increased incidence of stroke and heart attack, although the mechanism remains somewhat unclear. Cancer inducing air pollutants remain a concern, but in addition more recently there has been a rising interest in the presence of neurotoxins and endocrine disrupting substances in the environment.
\end{abstract}

\section{Introduction}

The $20^{\text {th }}$ century witnessed an enormous change in the sources of air pollution. The concept of air pollution as the combustion products of coal has gone along with chimney smoke and London fog. We must now consider secondary pollutants within photochemical smog that have no point sources. This new type of smog was first observed in Los Angeles during the Second World War. By the 1950s it was apparent that it was different, and a biochemist Arie HaagenSmit, studying damage to lettuce crops realised that this air pollution was caused by reactions of automobile exhaust vapours in sunlight. More recent times have seen a rise in use of diesel vehicles in European and more recently pressure to adopt biofuels.

There were, in parallel, great transformations in our understanding the health impacts of air pollutants and this forms the subject of the present article. These changes were not simply a monotonic increase in our understanding, they were transformations in how we see new effects of air pollution on human health. The transformations force a change in our vision of air pollution and the way in which health effects are included within the regulatory process. The aim here is not so much to detail the health affects of air pollutants, but to look at the variety of considerations that seem increasingly apparent.

\section{Noxious gases}

Although the Hippocratic writings tell us of the impact of air on health, the beginnings of a modern understanding of come from work on noxious gases and how the human body responds. In 1865, Claude Bernard showed that carbon monoxide had a strong affinity for haemoglobin and the formation of carboxyhaemoglobin was thoroughly investigated by both members of the famous father and son team, John Scott Haldane and J.B.S. Haldane, from the late 19th century [1]. Carbon monoxide has an affinity for with haemoglobin some 200-300 times greater than that of oxygen such that the equilibrium

$$
\mathrm{CO}+\mathrm{HbO}_{2} \leftrightarrows \mathrm{O}_{2}+\mathrm{HbCO}
$$


shifts to the right during $\mathrm{CO}$ exposure. The effectiveness of this process increases with exercise where the carboxyhaemoglobin ( $\mathrm{HbCO}$ ) can rise to $2.5-4.0 \%$. In smokers it can be as high as $10 \%$ and in a tent with a kerosene camping stove $21.5 \%$, while an ambient CO of $100 \mathrm{ppm}$ will produce $\sim 16 \% \mathrm{HbCO}$. Carboxyhaemoglobin has a half-life $\sim 4$ hours in the blood [see for review 2]. Such a clear biochemical understanding enables regulations to be set based on achieving reasonable levels for $\mathrm{HbCO}$, in blood typically $2.5-3.0 \%$ in the non-smoking population [3].

The infamous London smog exposed residents to a mixture of pollutants, smoke and $\mathrm{SO}_{2}$, and for a long time the health impacts were framed in terms of this combination [3]. The synergistic impact of $\mathrm{SO}_{2}$ and smoke was often interpreted in terms of the removal of the smoke particles from the respiratory system by the ciliary elevator of the bronchial tract. Sulfur dioxide reduced the effectiveness of this mechanisms just at a time when it was most required to clear the particles; hence the synergistic interaction. However, by the end of the $20^{\text {th }}$ century things had changed, although sulfur dioxide still has considerable impact on urban epidemiology (especially through short term, about 15 minute exposures to high concentration) the way the pollutant affects airway function, especially among people with pre-existing complaints. However, the increase in hospital admissions is not especially large: about $2 \%$ up for a $50 \mu \mathrm{gm}^{-3}[4]$. In contemporary air a synergistic interaction between sulfur dioxide and ozone seems most likely [5].

Nitrogen dioxide and ozone tend to affect both asthmatics and non-asthmatics suffer equally, whereas sulfur dioxide is much more likely to cause a narrowing of the airways in patients with asthma [4], although they may be sensitized to other allergens. Ozone targets the pulmonary system primarily by inducing biochemical effects via oxidation or the peroxidation of biomolecules. The lung damage can resemble "sunburn", while others have talked in loosely of increased lung leakiness.

We notice with the increasing understanding of the health impacts of these gases there was a focus on respiratory impacts on diseases such as asthma or bronchitis.

\section{Killer particles}

The apparent success of the UK Clean Air Act of 1956 had a number of dangers. Firstly the reduction in smoke and sulfur dioxide in the years after its passage may not have been a direct outcome of the Act [6]. Secondly the improvement in air quality may have enabled a kind of complacency to set in. True smoke was very much reduced, but few noticed an increase in fine particles some from the increasing presence of diesel-engine vehicles and a cleaner atmosphere allowed the formation of a summer haze of secondary particles.

In the early 1990's two important observations drew special attention to the importance of particles. Dockery et al. [7] famous six cities study showed a very clear correlation between mortality and morbidity and fine particle concentrations, although the mechanism was far from obvious. The widening adoption of the diesel engine, particularly in Europe has led to increasing amounts of fine diesel soot in urban atmospheres.

The increasing relevance of fine particles to health were made at a time when the European Commission was formulating European Air Quality Framework Directive 96/62/EC which aimed to regulate monitoring and management of air quality. We can find in the various drafts to the directive confusion over the terminology for particles in some of the earliest drafts that are called total suspended particulate matter and later this changes to $\mathrm{PM}_{10}$ (particles less than $10 \mu \mathrm{m}$ across) and even later to $\mathrm{PM}_{2.5}$ is mentioned.

A further problem within the early debates over the new directive was the variation in annual mean concentrations of particulate matter at urban background sites across the European Union. The appeared to decrease as one moved northward. A homogeneous Pan-European legislation would thus place higher burden on countries along the Mediterranean. Here high loads of Saharan dust, more active photochemistry and the warmer temperatures leading to greater emissions of volatile organic matter served to increase particle concentrations.

Respired particles less than $10 \mu \mathrm{m}$ in diameter make their way into the respiratory tract, while those less than about $3 \mu \mathrm{m}$ can ultimately be deposited in the alveoli. Although that much 


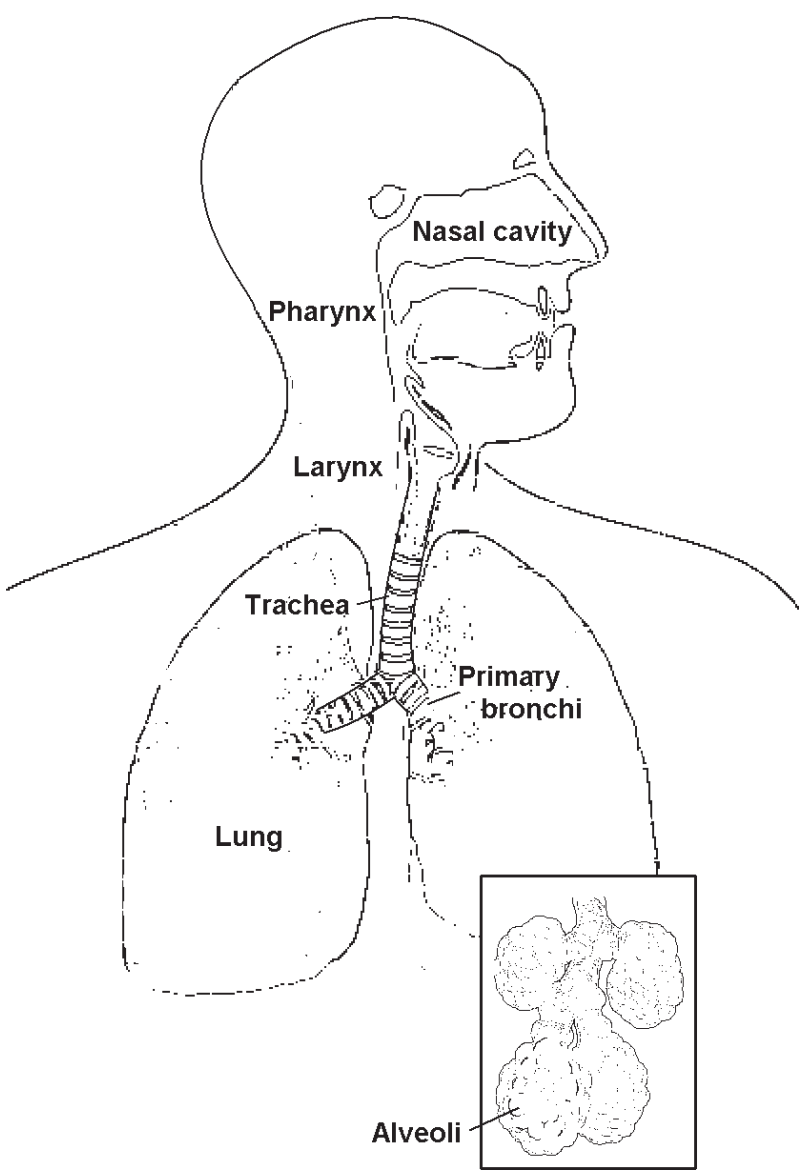

Fig. 1. A diagram of the lung, showing the upper respiratory tract that leads to lower respiratory tract, which starts with the trachea and splits in to primary bronchi and ever smaller branches that terminate in small sacs containing the alveoli (inset) where the exchange of gases with the blood takes place.

is fairly clear, the mode of action has been harder to unravel. In particular it was important to understand why the health outcomes came apparent as cardiovascular problems rather than respiratory disease. It is likely that the deposited particles are engulfed by macrophages within the alveoli (air sacs) of the lung (Fig. 1). This activity of the alveolar macrophages leads to the production of cytokines and coagulant factors, which can affect blood clotting and alter the coronary and cerebral microcirculation resulting in outcomes such as stroke and heath attacks.

It is currently important to understand the way in which particles cause health impacts because the legislation is based on particle size, yet it is not only particle size that is likely to determine the health impact of the particle. Some types of fine particle will have a stronger health effect than others. In Fig. 2 we see that particles from mobile sources have a much greater impact on death rate than those from coal or especially crustal sources.

In many ways legislating on the basis of particle size is troublesome. As Borm et al. [9] point out the "classic toxicology paradigm between exposure and response provides the justification for accurate measurement of exposure to underpin good epidemiological studies aimed at relating an environmental exposure to an adverse effect." Our lack of understanding of what constitutes a biologically effective dose of particles weakens this well established approach. However, recent studies have increasingly observed the ability of fine particles, especially those containing transition metals, to generate the hydroxyl radical and result in oxidative stress in 


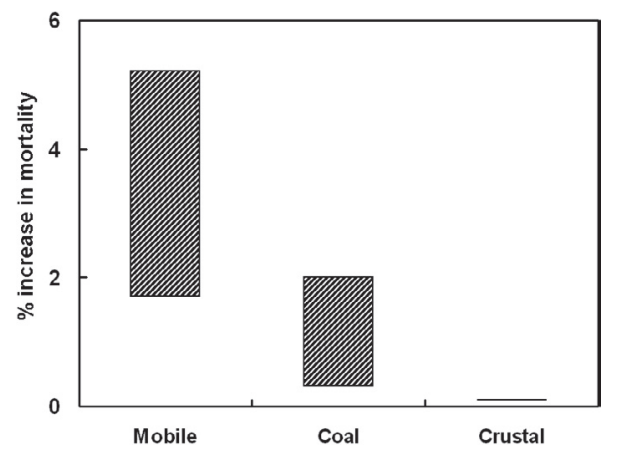

Fig. 2. The relationship impact of $10 \mu \mathrm{g} \mathrm{m}^{-3}$ increase in $\mathrm{PM}_{2.5}$ from various sources on daily mortality in U.S. cities [8].

the macrophages. The generation of such oxidants seem likely to be important measure of the health impact of particles.

We can also trace parallels in the health impacts of air pollutants. In the past they often seemed to have respiratory impact, but the modern understanding of the effects of fine particles indicates that they impose a broad cardio-vascular insult. This is an important transition, but we have also to recognise a number of other shifts in terms of health effects.

\section{Carcinogens}

Cancer is induced by a range of environment factors. It is seen as the uncontrolled cell growth, which develops slowly after a latent period. The presence of cancer is a characteristic of longlived populations. In our society where one in three is likely to develop some form of cancer during their lifetime, a high incidence of lung cancer has been closely associated with cigarette smoking. This has been the subject of increasing regulation in public spaces. In the urban atmosphere polycyclic aromatic hydrocarbons and 1,3-butadiene are carcinogens that affect the respiratory tract. Irritant gases may enhance the development of cancer rather than initiating it. The presence of benzene in air is likely to lead to cancer of the bone marrow.

The polycyclic aromatic hydrocarbons (PAHs) were very common in the atmosphere of cities with large emissions from domestic coal fireplaces. Percival Pott, a London physician, first recognised occupational cancer through exposure to coal tars (1775) during observations of scrotal and nasal cancers among chimney sweeps. The plight of young climbing boys who cleaned the chimney's of the rich is touchingly described on Charles Kingsley's childrens' tale, The Water-Babies (1863).

Compounds such as benzo(a)pyrene appear as a key carcinogen present in coal tar and explain the high incidence of cancer, in the past, among workers producing gas from. Other PAHs in coal wuch as benz(a)anthracene and dibenz(ah)anthracene are also potent carcinogens (Fig. 3). The metabolism of these polycyclic aromatic hydrocarbons (PAH) leads to highly reactive bay-region diol-epoxides, which are able to alkylate DNA and explains their effectiveness as carcinogens. Other carcinogens typical of urban air are benzene and 1,3-butadiene, which are often regulated.

Carcinogens create uncertainty because they may have no thresholds for injury. This means that no safe level can be established, so the guidelines are often framed in terms of the lifetime risk. In the case of benzene it is estimated that $1 \mu \mathrm{g} \mathrm{m}^{-3}$ of lifetime benzene exposure imposes a risk of $6 \times 10^{-6}[10]$. This would mean that if only one in a million were to die, the ambient benzene concentration would need to be $0.17 \mu \mathrm{g} \mathrm{m}^{-3}$. Although in the recent past guidelines have set allowable levels at $5 \mu \mathrm{g} \mathrm{m}^{-3}$, these are likely to become more stringent. The UK Air Quality Standards Regulations 2007 No. 64 will require this to be $1 \mu \mathrm{g} \mathrm{m}^{-3}$ to be the limit by the 1st January 2009. 


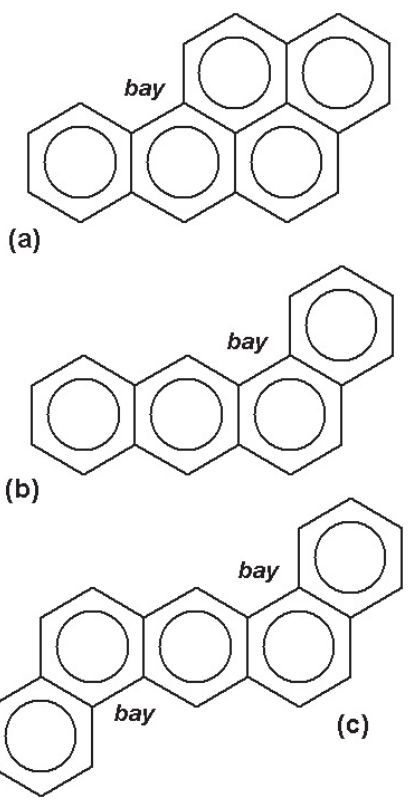

Fig. 3. PAH The polycyclic aromatic hydrocarbons (a) benzo(a)pyrene, (b) benz(a)anthracene and (c) dibenz(ah)anthracene illustrating the bay regions of the molecules.

\section{Non classical toxins}

As we have shown above, carcinogens although different from classical poisons have been known since the $18^{\text {th }}$ century. The late $20^{\text {th }}$ century saw interest in a range of subtle impacts of environmental toxins. While carcinogens create uncertainty over thresholds for injury, more novel toxins such as persistent organic pollutants have proved difficult to study. They include neurotoxins and also endocrine disruptors, which have been associated with a range of reproductive problems behaviour problems, impaired immune functions. More recently our exposure to a wide range of chemicals has promoted the controversial issue of multiple chemical sensitivity, where the impacts can be so difficult to define, that questions and remain as to whether the health outcomes are symptoms as all.

Pollutants such as lead, mercury, alcohol, nicotine, tobacco smoke are all potential neurotoxins, while and some pesticides can affect the developing foetus and impair normal brain development, with resultant learning and developmental disabilities. Such pollutants can also be responsible for neurodegenerative disorders among the elderly.

Lead, commonly found in many products and once present in the atmosphere through the use of the element as an anti-knock agent in fuels is perhaps the best known neurotoxin in urban air. As a human neurotoxin its neurological effects are likely to be irreversible. Childhood exposure to lead has been linked with attention deficits, hyperactivity anti-social behaviour and lower IQ. There often seem cultural references to this potential for hyperactivity, perhaps for example director in Michael Schultz's classic of film Cooley High (1975). This story of the frenetic pace of black high-school life hints seems a harbinger of a Ritalin-generation. Recently a study conducted over many years that found that higher blood lead levels correlated to more arrests, thus linking lead to criminal behaviour [11].

However, we need to be careful in seeing our society as largely driven by simple mechanistic interpretations such as poisoning. Delinquency is associated with a complex array of factors such as weak parent-child attachment, lax parental supervision, and school failure. Perhaps the most sweeping claim for the social impact of lead was that it brought about the decline of the Roman Empire. It is hardly surprising that this claim has not been widely accepted by scholars; John Scarborough has written of the myth of lead poisoning among the Romans [12]. Nevertheless the social impacts is seen in the relation between a broad range of stress 
related issues and air pollution discussed over many years by Evans and his co-workers including depression anxiety and hostility [13].

Persistent organic pollutants (POPs) have been seen as endocrine disruptors have been associated with a range of some of the behaviour problems already discussed along with reproductive issues and impaired immune functions. The US Environmental Protection Agency defines endocrine disruptors as substances which "interfere with the synthesis, secretion, transport, binding, action, or elimination of natural hormones in the body that are responsible for the maintenance of homeostasis (normal cell metabolism), reproduction, development, and/or behaviour." Many endocrine disruptors are thought to mimic hormones.

These endocrine disruptors are found in insecticides, herbicides, fumigants and fungicides. Some of these appear to have effects on oestrogen and testosterone related hormone systems in humans. Detergents, resins, and plasticizers can also have endocrine disrupting properties. Human epidemiology studies, which have examined the relationship between the manufacture and use of endocrine disruptors and health effects are far from conclusive. The potential presence in food and drink packaging has been of much concern. Bisphenol A used in the production of epoxy resins and polycarbonate plastics can mimic the effect of the hormone oestrogen in the body, by binding with oestrogen receptors. Utimately, Bisphenol A affects reproductive, neurological and immune systems. A further group of endocrine disruptors are the widely used phthalates (DINP and DEHP- dialkyl or alkyl aryl esters of 1,2-benzenedicarboxylic acid), which have increasingly been banned from consumer products.

The classic synthetic pesticide DDT (dichlorodiphenyltrichloroethane) a long known endocrine disruptor and is the subject of Rachel Carson's Silent Spring (1962). The infamous dioxin, a contaminant in the defoliant Agent Orange used in the Viet Nam War is often represented by its most harmful congener, 2,3,7,8-tetrachlorodibenzo-1,4-dioxin. This is a suspected endocrine disrupting chemical, along with the companion chlorinated furan. Dioxin fed directly to pregnant rats affects the sexual development, sperm production, and sexual behaviour in male pups. These chlorinated compounds can form during combustion processes especially where there are large quantities of chlorine environments. A notable case arose when pyres were used to destroy animal carcasses during the outbreak of foot and mouth disease in the United Kingdom in 2001. The pyres were made from wood, coal and railways sleepers. There was concern that the pentachlorophenol used as a wood preservative would be a potential precursor to dioxin. In the end the amounts released proved to be comparatively small and unlikely to cause substantial air quality exceedances [14].

It is clear that in recent years humans have been exposed to an increasingly wide range of chemicals. The potential impact of this has promoted the controversial issue of multiple chemical sensitivity (MCS), which has sometimes been compared to drug dependency. This is a highly controversial issue and considers that adverse physical reactions can arise from low level exposures to many common chemicals. The causes of this reaction include allergy, dysfunction of the immune system, neurobiological sensitization, and range of psychological explanations. Although the symptoms of MCS may be mild to disabling, they can be so variable and defined by the sufferer that they resist categorisation. The existence of multiple chemical sensitivity often receives little support from traditional medicine.

Much of exposure to many modern materials occurs in our own homes where there are consumer products and modern materials that can outgas [15]. Additionally there is likely to be a high concentration of pet dander and other common allergens. Furthermore we are also exposed to an array of cosmetics: perfume, talcum powder, hair spray, along with the irritant products from cooking, such as the capsaicins from peppers, although it is far from clear whether they pose serious health risks.

\section{Conclusions}

Our knowledge of the effects of air pollutants has improved and physiological understanding has increasingly been couched in terms of biochemistry. The $20^{\text {th }}$ century has seen significant transformations in the potential health outcomes of exposures to wide range of air pollutants. 
In the 1990s, concern shifted from the gaseous pollutants to fine particulate matter. This has led to an interest in cardiovascular responses rather than focussing on respiratory disease. Although occupational and environmental cancer has been known since the $18^{\text {th }}$ century problems of regulating substances with no threshold for harm remain. A range of novel contaminants has increased the potential for the presence of endocrine disruptors and neurotoxins in the environment. This has shifted the potential for effects on reproductive health and ultimately the neurological outcomes could have even broader social consequences. Clearly air pollution is not a problem that simply goes away. In our struggles and failures at improving air quality we are forced to reflect that life is a risky business and death is one of its few certainties.

\section{References}

1. G. Smith, Ann. New York Acad. Sci. 117, 684 (1964)

2. R.L. Maynard, R. Waller, in Air Pollution and Health, edited by S.T. Holgate, J.M. Samet, H.S. Koren, R.L. Maynard (Academic Press, London, 1999), p. 749

3. WHO, Air Quality Guidelines for Europe, 2nd edn. (WHO, Copenhagen, 1987)

4. J.G. Ayers, in Air Pollution and Health, edited by R.R. Hester, R.M. Harrison (Royal Chemical Society, Cambridge, 1998), p. 1

5. R.B. Schlesinger, in Air Pollution and Health, edited by S.T. Holgate, J.M. Samet, H.S. Koren, R.L. Maynard (Academic Press, London, 1999), p. 585

6. P. Brimblecombe, Weather 61, 311 (2006)

7. D.W. Dockery, C.A. Pope III, X. Xu, J.D. Spengler, J.H. Ware, M.E. Fay, B.G. Ferris Jr., F.E. Speizer, New Engl. J. Med. 329, 1753 (1993)

8. F. Laden, L.M. Neas, D.W. Dockery, J. Schwartz, Environ. Health Perspect. 108, 941 (2000)

9. P.J.A. Borm, F. Kelly, N. Künzli, R.P. Schins, K. Donaldson, Occup. Environ. Med. 64, 73 (2007)

10. J.C. Larsen, P.B. Larsen, in Air Pollution and Health, edited by R.R. Hester, R.M. Harrison (Royal Chemical Society, Cambridge, 1998), p. 33

11. J.P. Wright, K.N. Dietrich, M.D. Ris, R.W. Hornung, W. S.D., B.P. Lanphear, M. Ho, M.N. Rae, PLoS Med. 5, doi:10.1371/journal.pmed.0050101 (2008)

12. J. Scarborough, J. Hist. Med. 39, 469 (1984)

13. G.W. Evans, S.D. Colome, D.F. Shearer, Environ. Res. 45, 1 (1988)

14. I. Lowles, R. Hill, V. Auld, H. Stewart, C. Colhoun, Atmos. Environ. 36, 2901 (2002)

15. P. Brimblecombe, M. Cashmore, J. Phys. 6, 209 (2004) 
